\title{
Hotspots and Regional Variation in Smoking Prevalence Among 514 Districts in Indonesia: Analysis of Basic Health Research 2018
}

\author{
Dwi Hapsari ${ }^{1}$, Olwin Nainggolan ${ }^{1} \&$ Dian Kusuma ${ }^{2}$ \\ ${ }^{1}$ National Institute of Health Research and Development, Ministry of Health, Jakarta, Indonesia \\ ${ }^{2}$ Centre for Health Economics \& Policy Innovation, Imperial College Business School, London, UK \\ Correspondence: Dr. Dian Kusuma, Centre for Health Economics \& Policy Innovation, Imperial College Business \\ School, South Kensington Campus, London, SW7 2AZ. Tel: 44-(0)20-7589-5111. E-mail: \\ d.kusuma@imperial.ac.uk
}

Received: March 2, 2020 Accepted: July 6, 2020 Online Published: July 24, 2020

doi:10.5539/gjhs.v12n10p32 URL: https://doi.org/10.5539/gjhs.v12n10p32

\begin{abstract}
Background: The prevalence among adult men in Indonesia is among the highest in the world. Objective: Our study examines the hotspots and regional variation in smoking prevalence among 514 districts in Indonesia.

Methods: Taking advantage of the latest national health survey (Basic Health Research, Riskesdas 2018), which included smoking prevalence representative at the district level. We assessed the smoking prevalence among male and female adults (15+ years) and youth (13-14 years). We conducted geospatial analyses, using ArcMap 10.6, including quintile analysis (mapping the smoking prevalence by quintile for each district) and hotspot analysis (using Getis-Ord Gi* statistics to produce the hotspots, areas with a significantly higher density of advertisements). We also conducted quantitative analyses, using Stata 15.1, on geographic disparity, including region and urbanicity.
\end{abstract}

Results: We found huge disparity in smoking prevalence between districts, ranging from 9 to $81 \%$ for men, 0 to $50 \%$ for, 0 to $41 \%$ for women, and 0 to $50 \%$ for girls. We found up to 62 and 47 smoking hotspots among males and females, respectively. The poorest districts had significantly higher smoking prevalence among men but lower smoking prevalence among boys, and less educated districts had higher smoking prevalence among women.

Conclusion: There were significant hotspots and regional variations among 514 districts in Indonesia.

Keywords: hotspots, disparity, smoking, youth, adult, Indonesia

\section{Introduction}

Globally, cardiovascular diseases (CVDs) contributed to over 17 million deaths and 353 million disability-adjusted life years (DALYs) worldwide in 2016 (Hay et al., 2017; Naghavi et al., 2017). The second most important risk factor to CVDs, smoking, contributed up to 155 million DALY lost (Gakidou et al., 2017). In Indonesia, the burden is particularly high and increasing (Kusuma et al., 2019). Smoking was among the top contributors to DALY in 2017, particularly among Indonesian men (Mboi et al., 2018). Among adults (15+ years), the smoking prevalence is among the highest in the world (67\% and 2.7\% among males and females, respectively) (World Health Organization, 2018). Among youth (13-14 years), the prevalence was $36.2 \%$ and $4.3 \%$ among boys and girls, respectively, in 2014 (Kusumawardani et al., 2016).

However, there is a lack of national tobacco control efforts, which is partly because the government has not signed and ratified the Framework Convention on Tobacco Control (Kusuma et al., 2019). To date, the national program is limited to the flagship smoke-free policy that bans smoking, advertising, promotion, and sale in selected areas, including health facilities, educational facilities, places of worship, workplaces, public transport, markets, and parks. However, only two-thirds of districts adopted the policy during 2012-2018, with the compliance rates varied from 17\% in Jayapura city to 78\% in Bogor city (Wahidin et al., 2019; Wahyuti et al., 2019).

To help achieve the Sustainable Development Goals on reducing premature deaths (and disability) from CVDs, understanding geographic and socioeconomic disparities in the risk factors, including smoking is much needed (Capewell \& Graham, 2010; Di Cesare et al., 2013). There are many studies from high-income countries such as the United States, Canada, Germany, France, Japan, and Korea (Agaku, Odani, Okuyemi, \& Armour, 2019; 
Bricard, Jusot, Beck, Khlat, \& Legleye, 2016; Chang, Kang, Lim, Cho, \& Khang, 2019; Nagelhout et al., 2012; Reid, Hammond, \& Driezen, 2010; Tabuchi \& Kondo, 2017; Verlato et al., 2014; Völzke et al., 2006). Also, there are several studies from low and middle-income countries (LMICs), including multi-country studies (Bosdriesz, Mehmedovic, Witvliet, \& Kunst, 2014; Hosseinpoor, Parker, Tursan d'Espaignet, \& Chatterji, 2012; Li \& Guindon, 2013), as well as country-specific studies from Indonesia, China, Pakistan, India, Morocco, Malawi, Ghana, Romania, Turkey, Argentina, and Brazil (Amalia, Cadogan, Prabandari, \& Filippidis, 2019; Ayo-Yusuf, Olutola, \& Agaku, 2015; Barreto, De Figueiredo, \& Giatti, 2013; Cai, Wang, Fan, Cui, \& Golden, 2019; Chisha, Nwosu, \& Ataguba, 2019; Doku, Darteh, \& Kumi-Kyereme, 2013; El Rhazi et al., 2008; Hassoy, Ergin, \& Kunst, 2014; Kaleta, Usidame, Dziankowska-Zaborszczyk, \& Makowiec-Dąbrowska, 2015; Macias, Malmusi, \& Borrell, 2013; Masud \& Oyebode, 2018; Santero, Melendi, Hernández-Vásquez, \& Irazola, 2019; Thakur, 2013; Thakur et al., 2015; Yaya, Bishwajit, Shah, \& Ekholuenetale, 2017).

However, previous studies, especially from LMICs, are limited in at least two ways. First, while the multi-country studies included up to 63 countries, they used older data (almost two decades), including the Global Youth Tobacco Survey Data (GYTS, 2000-2007) and the World Health Survey (WHS, 2002-2004) (Bosdriesz et al., 2014; Hosseinpoor et al., 2012; Li \& Guindon, 2013). Second, previous studies focused on the relationship between smoking and socioeconomic indicators at the individual level. Analyses on the relationship at the higher level (e.g., district government) and geographic disparity are lacking. Such evidence is essential to monitor the progress of tobacco control efforts at the lowest policy level (e.g., in decentralized governments). This limitation is because many data sources were representative only at the national or regional level, including WHS, GYTS, Global Tobacco Adult Survey (GATS), and Demographic and Health Survey (DHS). Thus, our study aims to address this gap by examining the geographic and socioeconomic disparities in youth and adult smoking at districts in Indonesia.

\section{Methods}

This is a cross-sectional study employing geospatial and quantitative analyses among 514 districts in Indonesia. Geospatial analyses provided evidence on geographic variations of smoking prevalence, while the quantitative analyses provided the associations between socioeconomic indicators and smoking. The smoking data were from the Basic Health Research (Riskesdas) 2018, a nationally representative health survey conducted by the Ministry of Health. The sampling for smoking was representative at the district level. Detailed survey design and instrument are available elsewhere (National Institute of Health Research and Development, 2018). Smoking was defined as current smoking status of respondents among boys and girls aged 13-14 years and men and women aged 15 years and above, per the definitions of GYTS and GATS. The socioeconomic data were from the World Bank.

The geospatial analyses, conducted in ArcMap 10.6, included quintile and hotspot analysis. In the quintile analysis, we divided the smoking prevalence into fifths (lowest/highest quintile refers to $20 \%$ lowest/highest prevalence) and mapped the districts. In the hotspot analysis, we used the Hot Spot Analysis tool using Getis-Ord Gi* statistics to produce the hotspots, areas with a significantly higher density of advertisements (at a $95 \%$ significance level). Cold/hot spots are areas with significant spatial clustering of districts with higher/lower prevalence (at $95 \%$ level). Because the prevalence data are polygons of districts, we used the Contiguity Edges Only method, which analyzed only neighboring polygon features that share a boundary or overlap will influence computations for the target polygon feature.

We also conducted quantitative analyses on geographic disparity, including region and urbanicity. The National Planning Agency (Bappenas) divides the 34 provinces into seven regions, including Sumatera, Java, Kalimantan, Sulawesi, Nusa Tenggara, Maluku, and Papua. The last three regions are in the most eastern part and the least developed in the country. Moreover, we conducted quantitative analyses on socioeconomic disparity, including income and education indicators by urban and rural. We defined cities as urban and regents as rural; we used district-level poverty rate for income with the lowest rate as quintile 5; we used the net enrollment ratio of senior secondary for education with the highest ratio as quintile 5. We performed quantitative analyses in STATA 15.1.

\section{Results}

Table 1 shows district characteristics and smoking prevalence among youth and adults by district. In panel (a), there are 97 urban cities and 417 rural regents. By income, $79 \%$ of urban areas are richer $\left(4^{\text {th }}\right.$ and $5^{\text {th }}$ quintiles), while almost half $(48 \%)$ of rural areas are poorer $\left(1^{\text {st }}\right.$ and $2^{\text {nd }}$ quintiles $)$. Similarly, by education, $71 \%$ of the urban areas are most educated, while $47 \%$ of rural areas are least educated. In panel (b), the national prevalence of adult and youth smoking were $31.9 \%$ and $5.4 \%$, respectively, with a huge difference by sex. The prevalence among adult men and women was $61.4 \%$ and $2.3 \%$, while that among youth boys and girls were $10.2 \%$ and $0.2 \%$, respectively. Also, the prevalence is generally higher in rural, but only the differences in prevalence among adults and men are 
statistically significant.

Table 1. Characteristics of districts and smoking prevalence by areas in Indonesia, 2018

\begin{tabular}{|c|c|c|c|c|c|c|c|c|}
\hline & \multicolumn{2}{|l|}{ All } & \multicolumn{2}{|c|}{ Urban } & \multicolumn{2}{|c|}{ Rural } & \multirow{2}{*}{$\begin{array}{l}\text { Difference } \\
\%\end{array}$} & \\
\hline & $\mathrm{n}$ & $\%$ & $\mathrm{n}$ & $\%$ & $\mathrm{n}$ & $\%$ & & \\
\hline & {$[1]$} & {$[2]$} & {$[3]$} & [4] & {$[5]$} & {$[6]$} & {$[7]=[4-6]$} & \\
\hline \multicolumn{9}{|l|}{ (a) Characteristics (\#) } \\
\hline Sample size district & 514 & $100 \%$ & 97 & $100 \%$ & 417 & $100 \%$ & $0 \%$ & \\
\hline \multicolumn{9}{|l|}{ Region } \\
\hline Papua & 42 & $8 \%$ & 2 & $2 \%$ & 40 & $10 \%$ & $-8 \%$ & \\
\hline Maluku & 21 & $4 \%$ & 4 & $4 \%$ & 17 & $4 \%$ & $0 \%$ & \\
\hline Nusa Tenggara & 32 & $6 \%$ & 3 & $3 \%$ & 29 & $7 \%$ & $-4 \%$ & \\
\hline Java & 128 & $25 \%$ & 35 & $36 \%$ & 93 & $22 \%$ & $14 \%$ & \\
\hline Sumatera & 154 & $30 \%$ & 33 & $34 \%$ & 121 & $29 \%$ & $5 \%$ & \\
\hline Kalimantan & 56 & $11 \%$ & 9 & $9 \%$ & 47 & $11 \%$ & $-2 \%$ & \\
\hline \multirow[t]{2}{*}{ Sulawesi } & 81 & $16 \%$ & 11 & $11 \%$ & 70 & $17 \%$ & $-5 \%$ & \\
\hline & \multicolumn{2}{|l|}{514} & \multicolumn{2}{|l|}{97} & \multicolumn{2}{|l|}{417} & & \\
\hline \multicolumn{9}{|l|}{ Income/poverty } \\
\hline Q1 poor & 102 & $20 \%$ & 3 & $3 \%$ & 99 & $24 \%$ & $-21 \%$ & \\
\hline Q2 & 103 & $20 \%$ & 5 & $5 \%$ & 98 & $24 \%$ & $-18 \%$ & \\
\hline Q3 & 103 & $20 \%$ & 13 & $13 \%$ & 90 & $22 \%$ & $-8 \%$ & \\
\hline Q4 & 103 & $20 \%$ & 22 & $23 \%$ & 81 & $19 \%$ & $3 \%$ & \\
\hline \multirow[t]{2}{*}{ Q5 rich } & 103 & $20 \%$ & 54 & $56 \%$ & 49 & $12 \%$ & $44 \%$ & \\
\hline & \multicolumn{2}{|l|}{514} & \multicolumn{2}{|l|}{97} & \multicolumn{2}{|l|}{417} & & \\
\hline \multicolumn{9}{|l|}{ Education } \\
\hline Q1 least & 103 & $20 \%$ & 0 & $0 \%$ & 103 & $25 \%$ & $-25 \%$ & \\
\hline Q2 & 103 & $20 \%$ & 11 & $11 \%$ & 92 & $22 \%$ & $-11 \%$ & \\
\hline Q3 & 103 & $20 \%$ & 17 & $18 \%$ & 86 & $21 \%$ & $-3 \%$ & \\
\hline Q4 & 103 & $20 \%$ & 29 & $30 \%$ & 74 & $18 \%$ & $12 \%$ & \\
\hline \multirow[t]{2}{*}{ Q5 most } & 102 & $20 \%$ & 40 & $41 \%$ & 62 & $15 \%$ & $26 \%$ & \\
\hline & \multicolumn{2}{|l|}{514} & \multicolumn{2}{|l|}{97} & \multicolumn{2}{|l|}{417} & & \\
\hline \multicolumn{9}{|l|}{ (b) Smoking prevalence (\%) } \\
\hline Adult & $\mathrm{n} / \mathrm{a}$ & $31.9 \%$ & $\mathrm{n} / \mathrm{a}$ & $29.8 \%$ & $\mathrm{n} / \mathrm{a}$ & $32.4 \%$ & $-2.5 \%$ & * \\
\hline Men & $\mathrm{n} / \mathrm{a}$ & $61.4 \%$ & $\mathrm{n} / \mathrm{a}$ & $58.0 \%$ & $\mathrm{n} / \mathrm{a}$ & $62.2 \%$ & $-4.2 \%$ & $*$ \\
\hline Women & $\mathrm{n} / \mathrm{a}$ & $2.3 \%$ & $\mathrm{n} / \mathrm{a}$ & $2.1 \%$ & $\mathrm{n} / \mathrm{a}$ & $2.3 \%$ & $-0.2 \%$ & \\
\hline Youth & $\mathrm{n} / \mathrm{a}$ & $5.4 \%$ & $\mathrm{n} / \mathrm{a}$ & $5.3 \%$ & $\mathrm{n} / \mathrm{a}$ & $5.4 \%$ & $-0.1 \%$ & \\
\hline Boys & $\mathrm{n} / \mathrm{a}$ & $10.2 \%$ & $\mathrm{n} / \mathrm{a}$ & $10.2 \%$ & $\mathrm{n} / \mathrm{a}$ & $10.2 \%$ & $0.0 \%$ & \\
\hline Girls & $\mathrm{n} / \mathrm{a}$ & $0.2 \%$ & $\mathrm{n} / \mathrm{a}$ & $0.2 \%$ & $\mathrm{n} / \mathrm{a}$ & $0.2 \%$ & $0.0 \%$ & \\
\hline
\end{tabular}

Note. $\mathrm{Q}=$ Quintile, Urban=City, Rural=Regent. In panel (a), \%=proportion of column total; in panel (b), \%=mean smoking prevalence. The median smoking prevalence for adult, youth, men, and boys are similar to the mean, but the median for women (1.5\%) and girls $(0.0 \%)$ are different (indicating skewness). Data on district characteristics are from the World Bank and that on smoking prevalence are from Basic Health Survey 2018. Income quintile used district-level poverty rate (e.g. Q1 $=20 \%$ of districts with highest poverty rate). Bold numbers with asterisk $(*)$ show statistically significance (at $5 \%$ level) between urban and rural smoking prevalence. Adult $=15+$ years and youth $=13-14$ years (per GATS and GYTS definitions, respectively). 
Table 2. Characteristics of districts with the lowest/highest quintile and cold/hot spots of smoking prevalence

\begin{tabular}{|c|c|c|c|c|c|c|c|c|c|c|c|c|c|c|c|c|}
\hline & \multicolumn{8}{|c|}{ Lowest/Highest Quintile of Smoking Prevalence } & \multicolumn{8}{|c|}{ Cold and Hot Spots of Smoking Prevalence } \\
\hline & \multicolumn{2}{|c|}{ Men } & \multicolumn{2}{|c|}{ Boys } & \multicolumn{2}{|c|}{ Women } & \multicolumn{2}{|c|}{ Girls } & \multicolumn{2}{|c|}{ Men } & \multicolumn{2}{|c|}{ Boys } & \multicolumn{2}{|c|}{ Women } & \multicolumn{2}{|c|}{ Girls } \\
\hline & Q1 & Q5 & Q1 & Q5 & Q1 & Q5 & Q1 & Q5 & Cold & Hot & Cold & Hot & Cold & Hot & Cold & Hot \\
\hline & {$[1]$} & {$[2]$} & {$[4]$} & {$[5]$} & [7] & {$[8]$} & {$[10]$} & [11] & {$[12]$} & {$[13]$} & {$[14]$} & {$[15]$} & {$[16]$} & [17] & {$[18]$} & [19] \\
\hline $\mathrm{N}$ & 103 & 102 & 125 & 96 & 103 & 100 & 369 & 15 & 54 & 62 & 33 & 36 & - & 47 & - & 6 \\
\hline \multicolumn{17}{|l|}{ Region } \\
\hline Papua & 20 & 3 & 31 & 5 & 9 & 21 & 40 & 2 & 23 & 1 & 22 & 1 & - & 18 & - & 6 \\
\hline Maluku & 1 & 8 & 9 & 1 & 5 & 4 & 21 & 0 & 0 & 0 & 0 & 0 & - & 1 & - & 0 \\
\hline Nusa Tenggara & 3 & 12 & 6 & 5 & 15 & 1 & 32 & 0 & 0 & 4 & 0 & 0 & - & 0 & - & 0 \\
\hline Java & 24 & 26 & 8 & 46 & 33 & 20 & 103 & 10 & 11 & 18 & 0 & 29 & - & 10 & - & 0 \\
\hline Sumatera & 17 & 42 & 35 & 23 & 25 & 19 & 90 & 1 & 7 & 30 & 10 & 6 & - & 0 & - & 0 \\
\hline Kalimantan & 22 & 0 & 20 & 4 & 2 & 18 & 33 & 0 & 13 & 0 & 1 & 0 & - & 12 & - & 0 \\
\hline Sulawesi & 16 & 11 & 16 & 12 & 14 & 17 & 50 & 2 & 0 & 9 & 0 & 0 & - & 6 & - & 0 \\
\hline \multicolumn{17}{|l|}{ Income } \\
\hline Poorest quintile & 22 & 28 & 46 & 14 & 41 & 24 & 81 & 2 & 25 & 13 & 24 & 5 & - & 14 & - & 5 \\
\hline Q2 & 13 & 26 & 23 & 21 & 29 & 16 & 69 & 1 & 5 & 19 & 4 & 6 & - & 5 & - & 1 \\
\hline Q3 & 8 & 24 & 22 & 21 & 14 & 18 & 81 & 1 & 4 & 14 & 5 & 13 & - & 12 & - & 0 \\
\hline Q4 & 24 & 21 & 15 & 25 & 10 & 26 & 78 & 6 & 6 & 14 & 0 & 10 & - & 8 & - & 0 \\
\hline Richest quintile & 36 & 3 & 19 & 15 & 9 & 16 & 60 & 5 & 14 & 2 & 0 & 2 & - & 8 & - & 0 \\
\hline
\end{tabular}

Note. Q=Quintile; - =not applicable. Columns 1-11 show results for lowest and highest quintile; columns 12-19 show cold spots and hot spots of smoking prevalence. Income quintile used district-level poverty rate $(\mathrm{Q} 1=20 \%$ of districts with highest rate). 


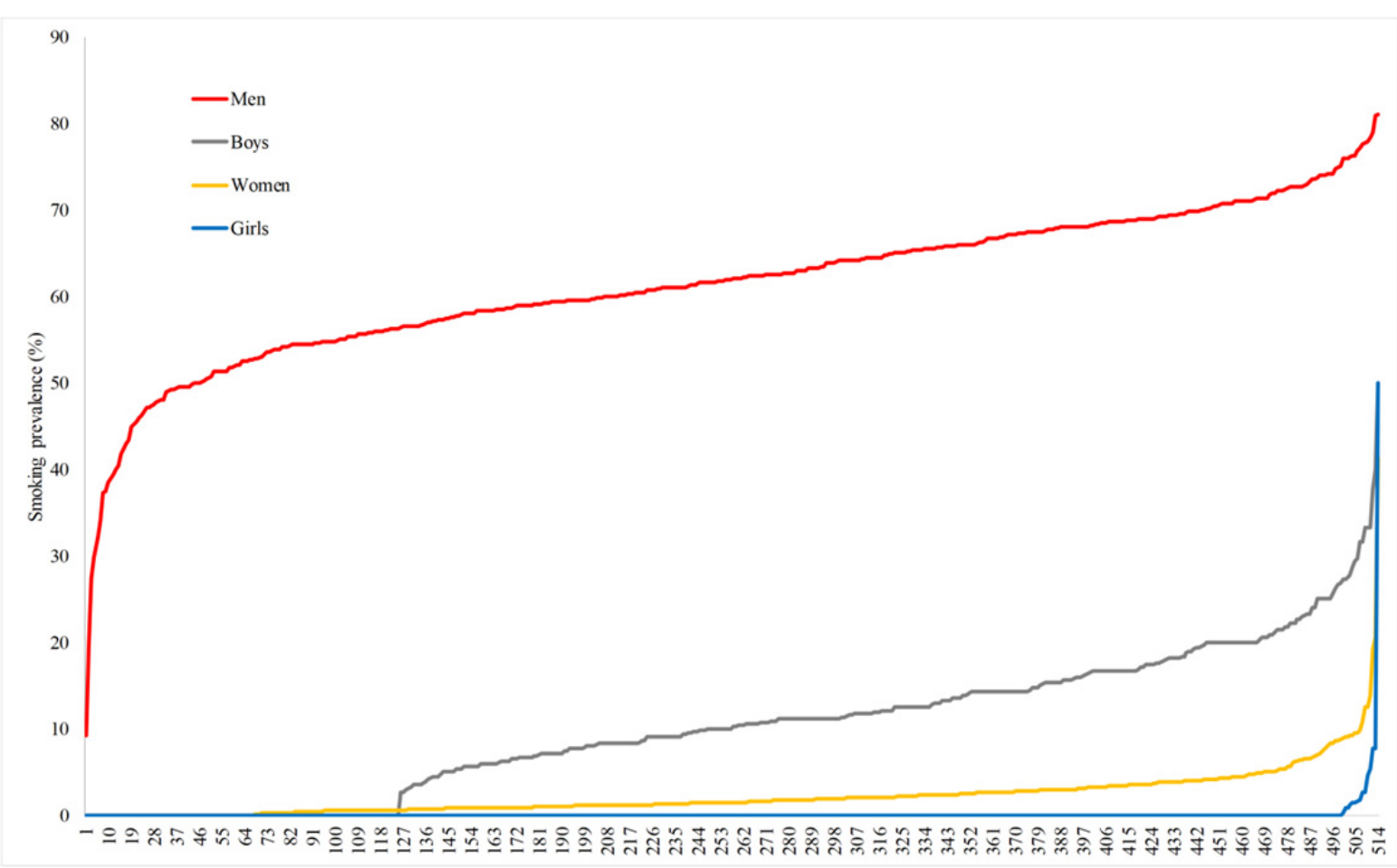

Note: The horizontal line is districts. The prevalence was sorted from the lowest to highest. The lowest (highest) values for men are $9.3 \%$ $(81 \%)$, for boys $0 \%(50 \%)$, for women $0 \%(41.3 \%)$, and for girls $0 \%(50 \%)$. There are 125,67 , and 499 districts with zero prevalence among boys, women, and girls (including 130 missing values for girls). Adult $=15+$ years and youth $=13-15$ years.

Figure 1. The prevalence of adult and youth smoking by districts in Indonesia, 2018

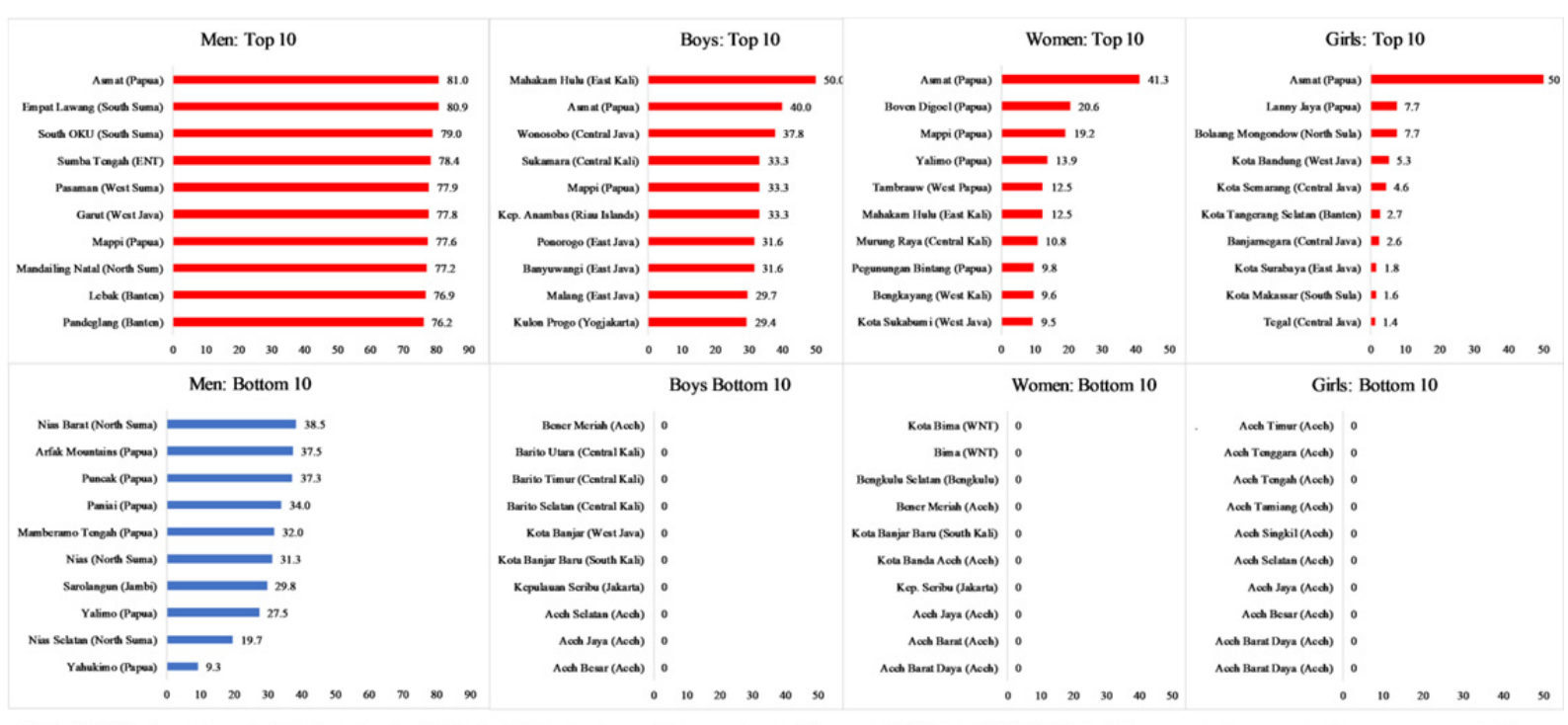

Note: Red/blue bars show districts (province) with the top/bottom ten in smoking prevalence. There are 125, 67, and 499 districts with zero prevalence among boys, women, and girls (including 130 missing values for girls); so, the districts shown are the first ten in alphabetical order. Adult $=15+$ years and youth $=13-15$ years.

Figure 2. Top and bottom 10 of smoking prevalence by districts in Indonesia, 2018

Figure 1 shows the smoking prevalence by districts sorted from the lowest to highest for men (red line), boys (gray), women (orange), and girls (blue). Results show a huge disparity in the prevalence by district with the lowest (highest) values for men $9.3 \%(81 \%)$, for boys $0 \%(50 \%)$, for women $0 \%(41.3 \%)$, and for girls $0 \%(50 \%)$. While all districts have higher prevalence for men, many districts with zero prevalence including 125 districts for boys, 67 for women, and 499 for girls. To better understand the extreme ends, Figure 2 shows the top ten and 
bottom ten districts. The red and blue bars show ten districts (province) with the highest and lowest prevalence. There are only four districts (1\%) with a prevalence for men less than $30 \%$ (about the average smoking prevalence among adult men in lower-middle-income countries) [38], leaving 510 districts (99\%) with higher prevalence. It is notable that up to five districts in Papua had the highest smoking prevalence for men, boys, women, and girls. Results also show five districts in Central Java and East Java provinces (which host the most powerful tobacco manufacturers in the country) that had the highest prevalence among boys.
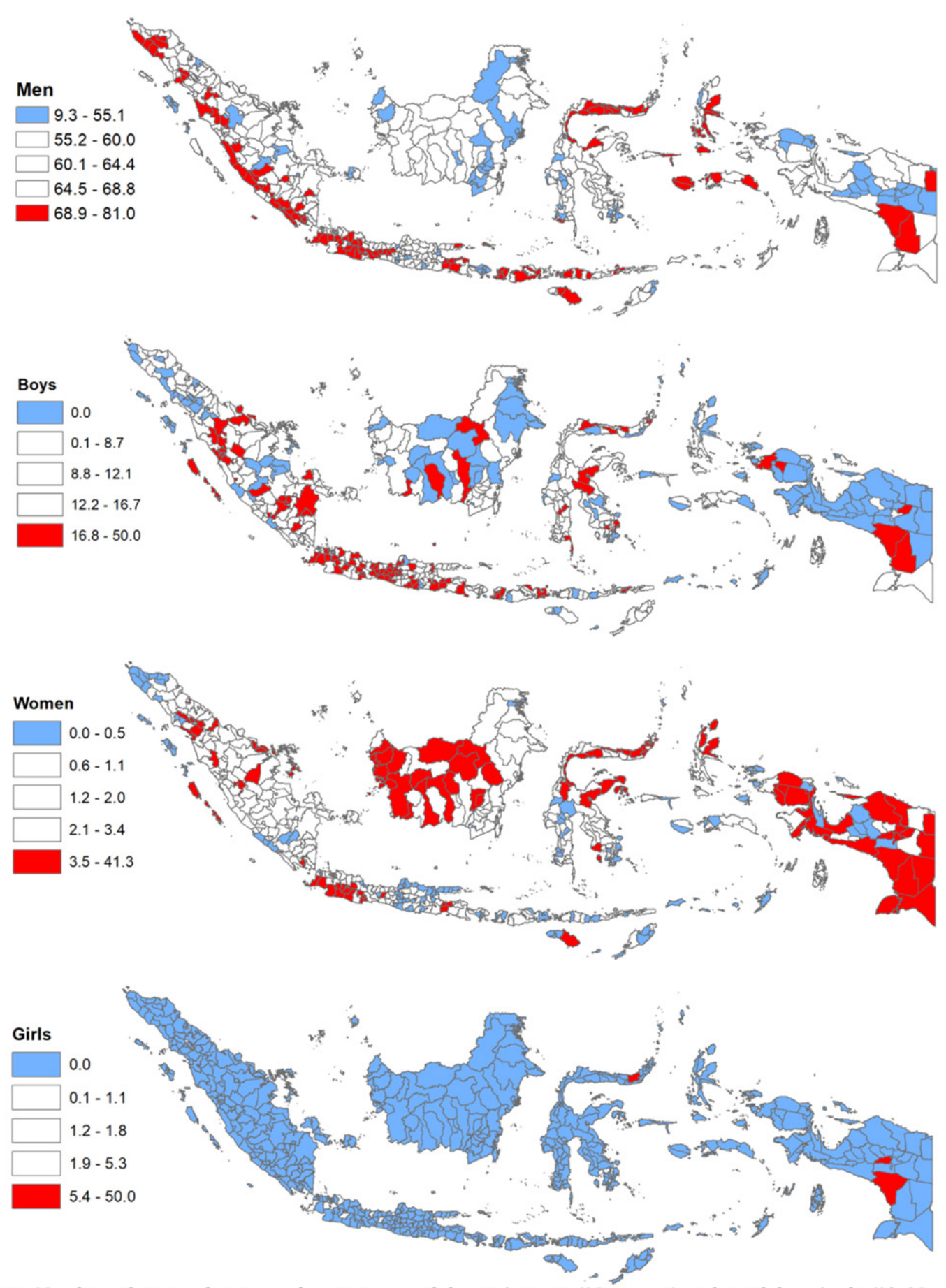

Note: Numbers show smoking prevalence among adult men/women (15+ years) and youth boys/girls (13-15 years). Red and blue show districts with highest (quintile 5) and lowest prevalence (quintile 1).

Figure 3. Disparity of smoking prevalence by district and sex in Indonesia, 2018 
To observe the overall district-level geographic disparity, Figure 3 maps the districts by the prevalence quintile and highlights those with the highest (quintile 5, red color) and lowest (quintile 1, blue color). For accuracy, we coupled the results with Table 2 that shows the characteristics of districts in each highlighted quintile (columns 1-11). Results show different geographic patterning in the prevalence among men, boys, women, and girls. For men, out of a total of 103 "blue districts" (Q1) and 102 "red districts" (Q5), there are red districts in all regions except for Kalimantan, which has 21 blue districts. For boys, out of 125 blue and 96 red districts, there are red districts in many parts of Java (46 districts) and Sumatera (23 districts). For women, out of 103 blue and 100 red districts, there are noticeable "red districts" in all regions except for Maluku and Nusa Tenggara. For girls, out of 15 red districts, ten are in Java, and two in Papua and Sulawesi.

So far, the results have not taken into account spatial clustering. Figure 4 maps the districts by hot spots (red color) and cold spots (blue color) of smoking prevalence. For accuracy, we coupled with Table 2 that shows the characteristics of hot/cold spot districts (columns 12-19). For men, out of 54 "cold districts" (cold spots) and 62 "hot districts" (hot spots), there are 13 and 23 cold districts in Kalimantan and Papua, respectively, while 18 and 30 hot districts in Java and Sumatera. For boys, out of 33 cold and 36 hot districts, there are 20 cold districts in Papua and 29 hot districts in Java. For women, out of 47 hot districts, there are 10, 12, and 18 hot districts in Java, Kalimantan, and Papua. For girls, out of 6 hot districts, all are in Papua.

Table 3. Regional and socioeconomic disparity in smoking prevalence

\begin{tabular}{|c|c|c|c|c|c|c|c|c|c|c|c|c|c|}
\hline & & \multicolumn{4}{|c|}{ All districts } & \multicolumn{4}{|l|}{ Urban } & \multicolumn{4}{|l|}{ Rural } \\
\hline & & Men & Boys & Women & Girls & Men & Boys & Women & Girls & Men & Boys & Women & Girls \\
\hline & & {$[1]$} & {$[2]$} & [3] & {$[4]$} & {$[5]$} & {$[6]$} & [7] & [8] & [9] & {$[10]$} & {$[11]$} & {$[12]$} \\
\hline \multicolumn{14}{|c|}{ Region } \\
\hline \multirow[t]{8}{*}{ (a) } & Papua & $53.3 \%$ & $4.7 \%$ & $5.3 \%$ & $1.4 \%$ & $48.9 \%$ & $3.3 \%$ & $1.7 \%$ & $0.0 \%$ & $53.6 \%$ & $4.7 \%$ & $5.5 \%$ & $1.4 \%$ \\
\hline & Maluku & $66.7 \%$ & $7.1 \%$ & $2.2 \%$ & $0.0 \%$ & $61.4 \%$ & $12.7 \%$ & $2.6 \%$ & $0.0 \%$ & $67.9 \%$ & $5.8 \%$ & $2.2 \%$ & $0.0 \%$ \\
\hline & Nusa & & & & & & & & & & & & \\
\hline & Tenggara & $65.7 \%$ & $9.8 \%$ & $0.8 \%$ & $0.0 \%$ & $60.8 \%$ & $12.6 \%$ & $0.6 \%$ & $0.0 \%$ & $66.2 \%$ & $9.5 \%$ & $0.8 \%$ & $0.0 \%$ \\
\hline & Sulawesi & $61.6 \%$ & $10.0 \%$ & $2.2 \%$ & $0.2 \%$ & $56.6 \%$ & $10.8 \%$ & $3.1 \%$ & $0.2 \%$ & $62.4 \%$ & $9.9 \%$ & $2.1 \%$ & $0.2 \%$ \\
\hline & Kalimantan & $56.3 \%$ & $8.4 \%$ & $3.1 \%$ & $0.0 \%$ & $49.9 \%$ & $4.9 \%$ & $1.3 \%$ & $0.0 \%$ & $57.5 \%$ & $9.1 \%$ & $3.4 \%$ & $0.0 \%$ \\
\hline & Sumatera & $63.6 \%$ & $9.9 \%$ & $1.8 \%$ & $0.0 \%$ & $60.0 \%$ & $9.6 \%$ & $1.7 \%$ & $0.0 \%$ & $64.6 \%$ & $10.0 \%$ & $1.9 \%$ & $0.0 \%$ \\
\hline & Java & $61.6 \%$ & $13.9 \%$ & $1.8 \%$ & $0.2 \%$ & $58.4 \%$ & $11.9 \%$ & $2.4 \%$ & $0.5 \%$ & $62.7 \%$ & $14.7 \%$ & $1.6 \%$ & $0.1 \%$ \\
\hline \multirow[t]{8}{*}{ (b) } & Papua & (ref) & & & & (ref) & & & & (ref) & & & \\
\hline & Maluku & $13.3 *$ & 2.4 & $-3.1 *$ & -1.4 & $12.5 *$ & 9.3 & 1 & 0 & $14.3 *$ & 1 & $-3.3 *$ & -1.4 \\
\hline & Nusa & & & & & & & & & & & & \\
\hline & Tenggara & $12.4^{*}$ & $5.1 *$ & $-4.5 *$ & $-1.4 *$ & $11.9 *$ & 9.2 & -1.1 & 0 & $12.7 *$ & $4.8^{*}$ & $-4.7 *$ & $-1.4 *$ \\
\hline & Sulawesi & $8.2 *$ & $9.3 *$ & $-3.5 *$ & $-1.2 *$ & $9.5 *$ & 8.5 & 0.7 & 0.5 & $9.2 *$ & $10.0 *$ & $-3.9 *$ & $-1.4^{*}$ \\
\hline & Kalimantan & $10.3^{*}$ & $5.3 *$ & $-3.5 *$ & $-1.4^{*}$ & $11.1 *$ & 6.3 & 0.1 & 0 & $11.0 *$ & $5.3 *$ & $-3.6 *$ & $-1.4 *$ \\
\hline & Sumatera & 2.9 & $3.7 *$ & $-2.2 \%$ & $-1.4^{*}$ & 1.1 & 1.6 & -0.3 & 0 & $3.9 *$ & $4.3 *$ & $-2.1 *$ & $-1.4^{*}$ \\
\hline & Java & $8.3^{*}$ & $5.3 *$ & $-3.1 *$ & $-1.2 *$ & 7.7 & 7.4 & 1.5 & 0.2 & 8.9* & $5.1 *$ & $-3.4 *$ & $-1.3 *$ \\
\hline \multicolumn{14}{|c|}{ Income } \\
\hline \multirow[t]{5}{*}{ (c) } & Q1 poor & $60.6 \%$ & $8.0 \%$ & $2.8 \%$ & $0.7 \%$ & $54.2 \%$ & $10.0 \%$ & $0.9 \%$ & $0.0 \%$ & $60.8 \%$ & $8.0 \%$ & $2.8 \%$ & $0.7 \%$ \\
\hline & Q2 & $63.6 \%$ & $10.1 \%$ & $1.6 \%$ & $0.0 \%$ & $60.7 \%$ & $9.7 \%$ & $2.9 \%$ & $0.0 \%$ & $63.7 \%$ & $10.1 \%$ & $1.6 \%$ & $0.0 \%$ \\
\hline & Q3 & $63.4 \%$ & $10.6 \%$ & $2.2 \%$ & $0.0 \%$ & $57.1 \%$ & $6.8 \%$ & $1.3 \%$ & $0.0 \%$ & $64.3 \%$ & $11.1 \%$ & $2.3 \%$ & $0.0 \%$ \\
\hline & Q4 & $61.4 \%$ & $11.6 \%$ & $2.6 \%$ & $0.1 \%$ & $57.9 \%$ & $11.5 \%$ & $2.0 \%$ & $0.0 \%$ & $62.4 \%$ & $11.6 \%$ & $2.8 \%$ & $0.2 \%$ \\
\hline & Q5 rich & $58.0 \%$ & $10.7 \%$ & $2.1 \%$ & $0.2 \%$ & $58.2 \%$ & $10.5 \%$ & $2.3 \%$ & $0.4 \%$ & $57.8 \%$ & $10.8 \%$ & $1.9 \%$ & $0.0 \%$ \\
\hline
\end{tabular}




\begin{tabular}{|c|c|c|c|c|c|c|c|c|c|c|c|c|c|}
\hline \multirow{5}{*}{ (d) } & \multirow{2}{*}{$\begin{array}{l}\text { Q1 poor } \\
\text { Q2 }\end{array}$} & \multicolumn{4}{|l|}{ (ref) } & \multicolumn{4}{|l|}{ (ref) } & \multicolumn{4}{|l|}{ (ref) } \\
\hline & & $3.0 *$ & 2.1 & $-1.1^{*}$ & -0.7 & 6.5 & -0.3 & 2 & 0 & $2.9^{*}$ & 2.2 & $-1.2 *$ & -0.7 \\
\hline & Q3 & $2.8^{*}$ & $2.6^{*}$ & -0.6 & -0.7 & 2.9 & -3.2 & 0.4 & 0 & $3.5^{*}$ & $3.2^{*}$ & -0.5 & -0.7 \\
\hline & Q4 & 0.8 & $3.6^{*}$ & -0.2 & -0.5 & 3.6 & 1.5 & 1.1 & 0 & 1.6 & $3.7^{*}$ & -0.1 & -0.5 \\
\hline & Q5 rich & $-2.6^{*}$ & $2.6^{*}$ & -0.6 & -0.5 & 3.9 & 0.5 & 1.4 & 0.4 & -3 & 2.8 & -0.9 & -0.7 \\
\hline \multicolumn{14}{|c|}{ Education } \\
\hline \multirow[t]{5}{*}{ (e) } & Q1 least & $61.6 \%$ & $10.2 \%$ & $3.7 \%$ & $0.8 \%$ & $\mathrm{n} / \mathrm{a}$ & $\mathrm{n} / \mathrm{a}$ & $\mathrm{n} / \mathrm{a}$ & $\mathrm{n} / \mathrm{a}$ & $61.6 \%$ & $10.2 \%$ & $3.7 \%$ & $0.8 \%$ \\
\hline & Q2 & $61.8 \%$ & $10.8 \%$ & $2.1 \%$ & $0.1 \%$ & $55.4 \%$ & $10.5 \%$ & $1.9 \%$ & $0.4 \%$ & $62.6 \%$ & $10.8 \%$ & $2.1 \%$ & $0.0 \%$ \\
\hline & Q3 & $62.4 \%$ & $9.8 \%$ & $1.9 \%$ & $0.0 \%$ & $56.5 \%$ & $8.6 \%$ & $2.0 \%$ & $0.1 \%$ & $63.5 \%$ & $10.0 \%$ & $1.9 \%$ & $0.0 \%$ \\
\hline & Q4 & $60.6 \%$ & $10.5 \%$ & $1.9 \%$ & $0.1 \%$ & $58.5 \%$ & $11.2 \%$ & $2.3 \%$ & $0.5 \%$ & $61.5 \%$ & $10.2 \%$ & $1.8 \%$ & $0.0 \%$ \\
\hline & Q5 most & $60.6 \%$ & $9.8 \%$ & $1.7 \%$ & $0.0 \%$ & $58.9 \%$ & $10.0 \%$ & $2.0 \%$ & $0.1 \%$ & $61.7 \%$ & $9.6 \%$ & $1.5 \%$ & $0.0 \%$ \\
\hline \multirow[t]{6}{*}{ (f) } & Q1 least & (ref) & & & & (ref) & & & & (ref) & & & \\
\hline & Q2 & 0.2 & 0.6 & $-1.6^{*}$ & -0.7 & 0 & 0 & 0 & 0 & 1 & 0.6 & $-1.5^{*}$ & -0.7 \\
\hline & Q3 & 0.8 & -0.4 & $-1.7^{*}$ & -0.8 & 1.1 & -1.9 & 0 & -0.3 & 1.9 & -0.2 & $-1.7^{*}$ & -0.8 \\
\hline & Q4 & -1 & 0.3 & $-1.7^{*}$ & -0.6 & 3.1 & 0.7 & 0.4 & 0.1 & -0.1 & 0 & $-1.9^{*}$ & -0.8 \\
\hline & Q5 most & -1 & -0.4 & $-2.0^{*}$ & -0.7 & 3.6 & -0.5 & 0.1 & -0.3 & 0.1 & -0.6 & $-2.2^{*}$ & -0.8 \\
\hline & $\mathrm{N}$ & 514 & 514 & 514 & 384 & 97 & 97 & 97 & 71 & 417 & 417 & 417 & 313 \\
\hline
\end{tabular}

Note. $\mathrm{Q}=$ Quintile. Panels a, c, e $=$ prevalence; panels $\mathrm{b}, \mathrm{d}, \mathrm{f}=$ differences in prevalence. Bold and * = statistical significance using OLS regression ( $5 \%$ level). Income quintile used district-level poverty rate (Q1=20\% of districts with highest rate).

Using quantitative analyses, Table 3 provides regional and socioeconomic disparities in smoking by district. Panels a, c, and e show the prevalence level by region, income, and education; panels b, d, and $\mathrm{f}$ show the prevalence differences compared to the reference districts (i.e., Papua, the poorest income quintile, and the least educated quintile). Compared to that in Papua, districts in all other regions had significantly higher smoking prevalence among men and boys, but they had a lower prevalence among women and girls. This patterning was particularly true in rural districts. Compared to that in the poorest income quintile, districts in the richest quintile had significantly lower smoking prevalence among men but had higher prevalence among boys. Compared to districts in the least educated quintile, districts in the most educated quintile had generally lower smoking prevalence among all groups but only among women that show significance. 

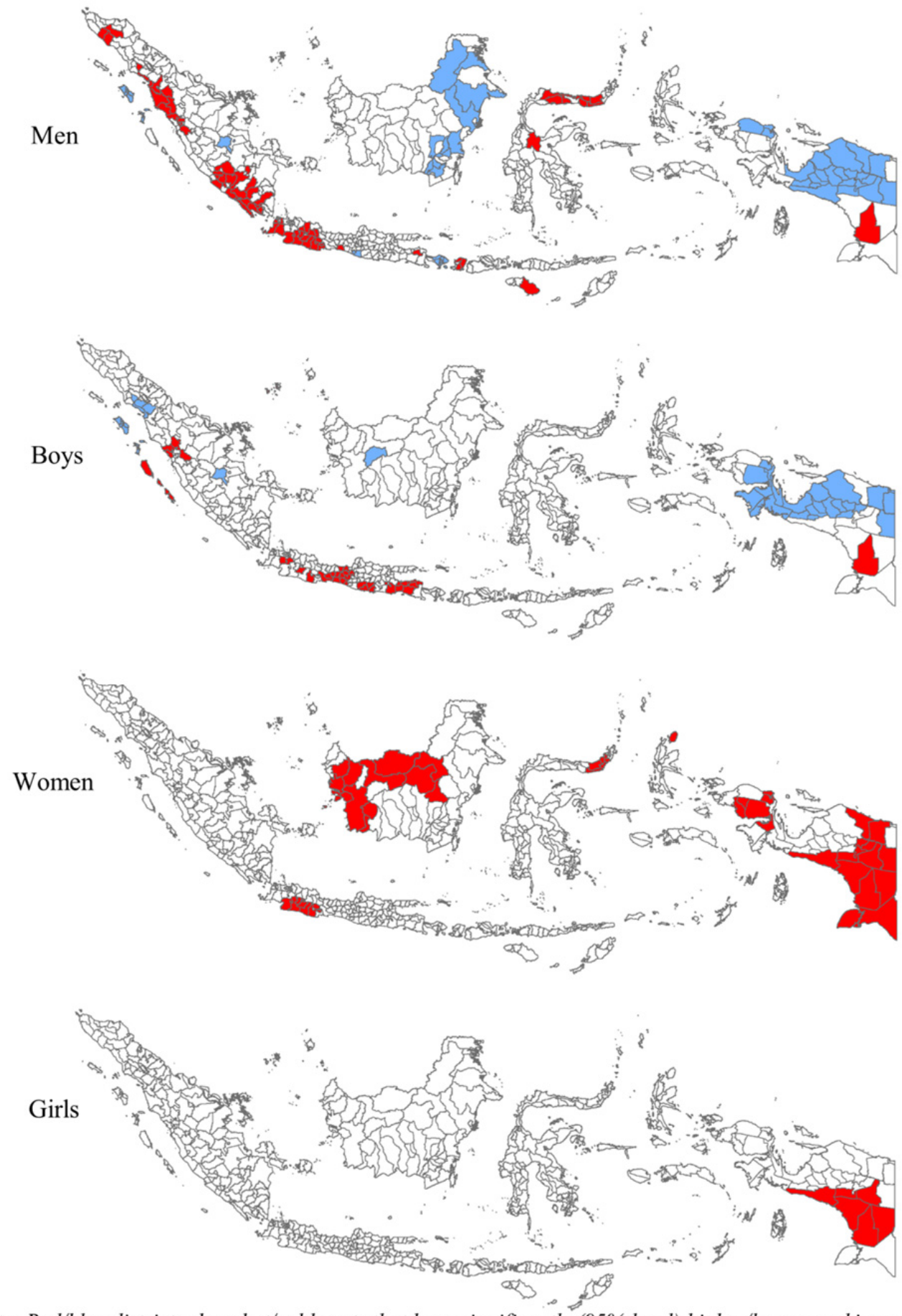

Note: Red/blue districts show hot/cold spots that have significantly (95\% level) higher/lower smoking prevalence. Hot Spot Analysis was in ArcMap 10.6. Adult men/women are 15+ years and youth boys/girls are 13-15 years.

Figure 4. Hot spots and cold spots of smoking prevalence by districts and sex in Indonesia, 2018

\section{Discussion and Conclusion}

In Indonesia, we found a very high smoking prevalence among adult men (61.4\%) with a huge range of almost nine times (from $9.3 \%$ to $81 \%$ ). Unfortunately, except for the four outlier districts with a prevalence of less than $30 \%$, all 510 districts had higher prevalence. Similarly, we found a relatively high prevalence among boys $(10.2 \%)$ with a huge range from zero (in 125 districts) to $50 \%$ prevalence. Among females, while we found relatively lower overall prevalence among women and girls, there are many districts with relatively high prevalence. Ten districts had a prevalence among women at $10 \%$ or more and five districts with the prevalence among girls at $5 \%$ or more. 
For policy, this evidence supports the need for more tobacco control efforts among men in all districts, boys in a majority of districts, and women and girls in selected districts.

We also found a significant geographic disparity in the prevalence of smoking. For men and boys, districts in all other regions had higher prevalence than districts in the Papua region (the most disadvantaged region in the country). These associations still hold even after controlling for income and education indicators. Moreover, $29 \%$ and $48 \%$ of hot spot districts were in the Sumatera and Java regions (among the most developed regions). While the fact that the two regions have the largest number of districts may partly explain this, the evidence is still supportive of the need for more tobacco control efforts in those areas. A recent study on the smoke-free policy showed that only $69 \%$ of districts in Java and Sumatera adopted during $2012-2018$, compared to $75 \%$ and $83 \%$ in Kalimantan and Sulawesi (Wahidin et al., 2019). Also, there is a potential to learn from other regions such as Kalimantan and Papua with more cold spot districts.

In contrast, districts in Papua had a higher prevalence of smoking among women and girls than districts in all other regions. In the top ten districts with the highest prevalence among women and girls, five and two districts were from Papua. Moreover, $38 \%$ and $100 \%$ of hot spot districts for women and girls were in the Papua. The very low prevalence of current smokers among females may be due to under-reporting in areas where smoking is considered an unacceptable practice among females for cultural or religious reasons, similar to the evidence from South Korea and Iran (Jung-Choi, Khang, \& Cho, 2012; Sarraf-Zadegan, 2004). For policy, more efforts should be made, especially in the many districts with relatively high prevalence. A recent study showed a very low compliance rate $(17 \%)$ to the smoke-free policy among selected facilities in Jayapura city (Wahyuti et al., 2019). Also, there is a potential to learn from other regions that have relatively lower prevalence.

Moreover, in terms of socioeconomic disparities, we found significant income disparities in smoking by district among men and boys. Districts in the poorest quintile had a higher smoking prevalence among men, but, in contrast, districts in the richest quintile had higher prevalence among boys. For policy, this might be due to more exposure to tobacco advertising and retailers including in the new media. Studies have shown high visibility of outdoor tobacco advertising around educational facilities in Surabaya city (East Java) and Semarang city (Central Java) (Megatsari, Ridlo, Amir, \& Kusuma, 2019; Nurjanah et al., 2020). Another study has also shown a higher density of cigarette retailers around formal and informal educational facilities in Depok city (West Java) (Adisasmito et al., 2020). Moreover, we also found significant educational disparities in smoking only among women with districts in the most educated quintile had lower smoking prevalence. However, these results are only statistically significant in rural districts. While this may be due to the lower sample of urban cities (97 urban cities, 417 rural regents), this may also indicate less variations in the cities in terms of smoking, income indicator, and educational indicator.

To our knowledge, this is the first study to examine geographic and socioeconomic disparities at the district level (the second level below national). It was possible because the data sampling was representative not only at the national level but also at the district level. Also, this is highly relevant for national planning as well as local policymaking, especially in decentralized settings. Our study has at least two limitations. First, because the analysis was broken down by youth/adult and then further by male/female, there were 130 districts with missing values for girls (13-14 years). Second, given the ecologic study design, the results should not be interpreted at the individual level. Despite these limitations, our findings have important policy implications for Indonesia and beyond.

Funding

None.

\section{Ethical Approval}

National Institute of Health Research and Development, Ministry of Health

\section{Contribution}

DH, ON, DK conceived the study, collected the data, and conducted data analyses. DK drafted and DH, ON provided inputs to the manuscript. All authors approved the final version of the manuscript.

\section{Acknowledgements}

The permission to use Riskesdas from the National Institute of Health Research and Development is gratefully acknowledged. 


\section{Competing Interests Statement}

The authors declare that there are no competing or potential conflicts of interest.

\section{References}

Adisasmito. (2020). Density of cigarette retailers around formal and informal educational facilities: Geospatial analysis in Indonesia. Int $J$ Tuberc Lung Dis, In Press.

Agaku, I. T., Odani, S., Okuyemi, K. S., \& Armour, B. (2019). Disparities in current cigarette smoking among US adults, 2002-2016. Tobacco Control. https://doi.org/10.1136/tobaccocontrol-2019-054948

Amalia, B., Cadogan, S. L., Prabandari, Y. S., \& Filippidis, F. T. (2019). Socio-demographic inequalities in cigarette smoking in Indonesia, 2007 to 2014. Preventive Medicine, 123, 27-33. https://doi.org/10.1016/j.ypmed.2019.02.025

Ayo-Yusuf, O. A., Olutola, B. G., \& Agaku, I. T. (2015). Cigarette Smoking Trends and Social Disparities Among South African Adults, 2003-2011. Nicotine \& Tobacco Research, 17(8), 1049-1055. https://doi.org/10.1093/ntr/ntu264

Barreto, S. M., De Figueiredo, R. C., \& Giatti, L. (2013). Socioeconomic inequalities in youth smoking in Brazil. BMJ Open, 3(12). https://doi.org/10.1136/bmjopen-2013-003538

Bosdriesz, J. R., Mehmedovic, S., Witvliet, M. I., \& Kunst, A. E. (2014). Socioeconomic inequalities in smoking in low and mid income countries: Positive gradients among women? International Journal for Equity in Health, 13(1). https://doi.org/10.1186/1475-9276-13-14

Bricard, D., Jusot, F., Beck, F., Khlat, M., \& Legleye, S. (2016). Educational inequalities in smoking over the life cycle: an analysis by cohort and gender. International Journal of Public Health, 61(1), 101-109. https://doi.org/10.1007/s00038-015-0731-6

Cai, L., Wang, X. M., Fan, L. M., Cui, W. L., \& Golden, A. R. (2019). Socioeconomic disparities in prevalence and behaviors of smoking in rural Southwest China. BMC Public Health, 19(1). https://doi.org/10.1186/s12889-019-7455-0

Capewell, S., \& Graham, H. (2010). Will cardiovascular disease prevention widen health inequalities? PLoS Medicine, 7(8). https://doi.org/10.1371/journal.pmed.1000320

Chang, Y., Kang, H.-Y., Lim, D., Cho, H.-J., \& Khang, Y.-H. (2019). Long-term trends in smoking prevalence and its socioeconomic inequalities in Korea, 1992-2016. International Journal for Equity in Health, 18(1), 148. https://doi.org/10.1186/s12939-019-1051-x

Chisha, Z., Nwosu, C. O., \& Ataguba, J. E. O. (2019). Decomposition of socioeconomic inequalities in cigarette smoking: The case of Namibia. International Journal for Equity in Health, 18(1). https://doi.org/10.1186/s12939-019-0912-7

Di Cesare, M., Khang, Y. H., Asaria, P., Blakely, T., Cowan, M. J., Farzadfar, F., ... Ezzati, M. (2013). Inequalities in non-communicable diseases and effective responses. The Lancet. Lancet Publishing Group. https://doi.org/10.1016/S0140-6736(12)61851-0

Doku, D., Darteh, E. K. M., \& Kumi-Kyereme, A. (2013). Socioeconomic inequalities in cigarette smoking among men: evidence from the 2003 and 2008 Ghana demographic and health surveys. Archives of Public Health, 71(1), 9. https://doi.org/10.1186/0778-7367-71-9

El Rhazi, K., Nejjari, C., Berraho, M., Serhier, Z., Tachfouti, N., El Fakir, S., ... Slama, K. (2008). Inequalities in smoking profiles in Morocco: the role of educational level. Int J Tuberc Lung Dis, Nov;12(11).

Gakidou, E., Afshin, A., Abajobir, A. A., Abate, K. H., Abbafati, C., Abbas, K. M., ... Murray, C. J. L. (2017). Global, regional, and national comparative risk assessment of 84 behavioural, environmental and occupational, and metabolic risks or clusters of risks, 1990-2016: A systematic analysis for the Global Burden of Disease Study 2016. The Lancet, 390(10100), 1345-1422. https://doi.org/10.1016/S0140-6736(17)32366-8

Hassoy, H., Ergin, I., \& Kunst, A. E. (2014). Socioeconomic inequalities in current daily smoking in five Turkish regions. International Journal of Public Health, 59(2), 251-260. https://doi.org/10.1007/s00038-013-0476-z

Hay, S. I., Abajobir, A. A., Abate, K. H., Abbafati, C., Abbas, K. M., Abd-Allah, F., .. Bryane, C. E. G. (2017). Global, regional, and national disability-adjusted life-years (DALYs) for 333 diseases and injuries and healthy life expectancy (HALE) for 195 countries and territories, 1990-2016: A systematic analysis for the 
Global Burden of Disease Study 2016. The Lancet, 390(10100), 1260-1344. https://doi.org/10.1016/S0140-6736(17)32130-X

Hosseinpoor, A. R., Parker, L. A., Tursan d'Espaignet, E., \& Chatterji, S. (2012). Socioeconomic Inequality in Smoking in Low-Income and Middle-Income Countries: Results from the World Health Survey. PLoS ONE, 7(8), e42843. https://doi.org/10.1371/journal.pone.0042843

Jung-Choi, K. H., Khang, Y. H., \& Cho, H. J. (2012). Hidden female smokers in Asia: A comparison of self-reported with cotinine-verified smoking prevalence rates in representative national data from an Asian population. Tobacco Control, 21(6), 536-542. https://doi.org/10.1136/tobaccocontrol-2011-050012

Kaleta, D., Usidame, B., Dziankowska-Zaborszczyk, E., \& Makowiec-Dąbrowska, T. (2015). Socioeconomic Disparities in Age of Initiation and Ever Tobacco Smoking: Findings from Romania. Central European Journal of Public Health, 23(4), 299-305. https://doi.org/10.21101/cejph.a4067

Kusuma, D., Kusumawardani, N., Ahsan, A., Sebayang, S. K., Amir, V., \& Ng, N. (2019). On the verge of a chronic disease epidemic: comprehensive policies and actions are needed in Indonesia. International Health, $11(6), 422-424$.

Kusumawardani, N., Rachmalina, D. S., dr Yuana Wiryawan, Ms., Dra Athena Anwar, Mk., Kartika Handayani, Ms., Rofingatul Mubasyiroh, Ms., ... Meda Permana, M. (2016). Perilaku Berisiko Kesehatan Pada Pelajar SMP Dan SMA Di Indonesia Disusun oleh. Retrieved from https://www.who.int/ncds/surveillance/gshs/GSHS_2015_Indonesia_Report_Bahasa.pdf

Li, D. X., \& Guindon, G. E. (2013). Income, income inequality and youth smoking in low- and middle-income countries. Addiction, 108(4), 799-808. https://doi.org/10.1111/add.12075

Macias, F., Malmusi, D., \& Borrell, C. (2013). Different Patterns by Age-Group and Gender of Socioeconomic Inequalities in Smoking in Colombia. Nicotine \& Tobacco Research, 15(10), 1745-1755. https://doi.org/10.1093/ntr/ntt055

Masud, H., \& Oyebode, O. (2018). Inequalities in smoking prevalence: a missed opportunity for tobacco control in Pakistan. Journal of Public Health, 40(2), 271-278. https://doi.org/10.1093/pubmed/fdx044

Mboi, N., Murty Surbakti, I., Trihandini, I., Elyazar, I., Houston Smith, K., Bahjuri Ali, P., ... Hay, S. I. (2018). On the road to universal health care in Indonesia, 1990-2016: a systematic analysis for the Global Burden of Disease Study 2016. The Lancet, 392(10147), 581-591. https://doi.org/10.1016/S0140-6736(18)30595-6

Megatsari, H., Ridlo, I., Amir, V., \& Kusuma, D. (2019). Visibility and hotspots of outdoor tobacco advertisement around educational facilities without an advertising ban: Geospatial analysis in Surabaya City, Indonesia. Tobacco Prevention \& Cessation, 5(October). https://doi.org/10.18332/tpc/112462

Nagelhout, G. E., De Korte-De Boer, D., Kunst, A. E., Van Der Meer, R. M., De Vries, H., Van Gelder, B. M., \& Willemsen, M. C. (2012). Trends in socioeconomic inequalities in smoking prevalence, consumption, initiation, and cessation between 2001 and 2008 in the Netherlands. Findings from a national population survey. BMC Public Health, 12(1). https://doi.org/10.1186/1471-2458-12-303

Naghavi, M., Abajobir, A. A., Abbafati, C., Abbas, K. M., Abd-Allah, F., Abera, S. F., .. Murray, C. J. L. (2017). Global, regional, and national age-sex specifc mortality for 264 causes of death, 1980-2016: A systematic analysis for the Global Burden of Disease Study 2016. The Lancet, 390(10100), 1151-1210. https://doi.org/10.1016/S0140-6736(17)32152-9

National Institute of Health and Research Development. [Report of Riskesdas 2018]. Jakarta, Indonesia: MoH, $2018 . \quad$ http: //labmandat.litbang.depkes.go.id/images/ download/laporan/RKD/2018/Laporan_Nasional_RKD2018_ FINAL.pdf Accessed July 2020.

Nurjanah, N., Manglapy, Y., Handayani, S., Ahsan, A., Sutomo, R., Dewi, F. S. T., .. \& Kusuma, D. (2020). Density of tobacco advertising around schools Int J Tuberc Lung Dis 24(7).

Reid, J. L., Hammond, D., \& Driezen, P. (2010). Socio-economic status and smoking in Canada, 1999-2006: Has there been any progress on disparities in Tobacco use? Canadian Journal of Public Health, 101(1), 73-78. https://doi.org/10.1007/bf03405567

Santero, M., Melendi, S., Hernández-Vásquez, A., \& Irazola, V. (2019). Socio-economic inequalities in smoking prevalence and involuntary exposure to tobacco smoke in Argentina: Analysis of three cross-sectional nationally representative surveys in 2005, 2009 and 2013. PLOS ONE, 14(6), e0217845. https://doi.org/10.1371/journal.pone.0217845 
Sarraf-Zadegan, N. (2004). Tobacco use among Iranian men, women and adolescents. The European Journal of Public Health, 14(1), 76-78. https://doi.org/10.1093/eurpub/14.1.76

Tabuchi, T., \& Kondo, N. (2017). Educational inequalities in smoking among Japanese adults aged 25-94 years: Nationally representative sex- and age-specific statistics. Journal of Epidemiology, 27(4), 186-192. https://doi.org/10.1016/j.je.2016.05.007

Thakur. (2013). Socioeconomic inequality in the prevalence of smoking and smokeless tobacco use in India. Asian Pacific Journal of Cancer Prevention. Retrieved from $\mathrm{http} / /$ journal.waocp.org/?sid=Entrez:PubMed\&id=pmid:24377634\&key=2013.14.11.6965

Thakur, J., Prinja, S., Bhatnagar, N., Rana, S., Sinha, D., \& Singh, P. (2015). Widespread inequalities in smoking \&amp; smokeless tobacco consumption across wealth quintiles in States of India: Need for targeted interventions. Indian Journal of Medical Research, 141(6), 789. https://doi.org/10.4103/0971-5916.160704

Verlato, G., Accordini, S., Nguyen, G., Marchetti, P., Cazzoletti, L., Ferrari, M., ... de Marco, R. (2014). Socioeconomic inequalities in smoking habits are still increasing in Italy. BMC Public Health, 14(1), 879. https://doi.org/10.1186/1471-2458-14-879

Völzke, H., Neuhauser, H., Moebus, S., Baumert, J., Berger, K., Stang, A., ... Döring, A. (2006). Urban-rural disparities in smoking behaviour in Germany. BMC Public Health, 6(1), 146. https://doi.org/10.1186/1471-2458-6-146

Wahidin, M., Hidayat, M. S., Arasy, R. A., Amir, V., \& Kusuma, D. (2019). Geographic, socioeconomic disparity and policy determinant of the adoption of smoke-free policy by districts in Indonesia. Int J Tuberc Lung Dis 24(4), 383-398.

Wahyuti, W., Hasairin S. K., Mamoribo, S. N., Ahsan, A. K. D. (2019). Monitoring compliance and examining challenges of a smoke-free policy in Jayapura, Indonesia. J Prev Med Public Health, 52, 427-432.

World Health Organization. (2018). Heart disease and stroke are the commonest ways by which tobacco kills people FACTSHEET 2018 INDONESIA 264.0 million. Retrieved from http://www.searo.who.int/tobacco/data/ino_rtc_reports,

Yaya, S., Bishwajit, G., Shah, V., \& Ekholuenetale, M. (2017). Socioeconomic Disparities in Smoking Behavior and Early Smoking Initiation Among Men in Malawi. Tobacco Use Insights, 10, 1179173X1772629. https://doi.org/10.1177/1179173x17726297

\section{Copyrights}

Copyright for this article is retained by the author(s), with first publication rights granted to the journal.

This is an open-access article distributed under the terms and conditions of the Creative Commons Attribution license (http://creativecommons.org/licenses/by/4.0/). 